\title{
RISK ATTITUDE IN REAL DECISION PROBLEMS•
}

\author{
by \\ Fabrizio Botti ${ }^{\#}$, Anna Conte ${ }^{\S}$, Daniela Di Cagno ${ }^{£}$ and Carlo D’Ippoliti*
}

JEL classification: C15, C23, C25, D81

Keywords: Panel Data, Unobserved heterogeneity, Choice under risk

\begin{abstract}
Experimental economics focuses on eliciting preferences, studying individuals one at a time to take into account their heterogeneity. Experiments have the appealing property of collecting enough observations to perform such an analysis. In real word, and in natural experiments, individuals cannot be observed according to experimenters' needs. We propose a method that aggregates over individuals taking into account their heterogeneity. Using data from a natural experiment, we estimate three models of decision making under risk: Expected Utility, Rank-Dependent Expected Utility and Regret-Rejoice. Our results show that individual-wise analyses can be substituted by pooled approaches without losing information about individual heterogeneity.

\# LUISS Guido Carli, Via O.Tommasini 1, 00162 Roma, Italy; fax: (39)06.86.506.605; telephone: (39)06.85.225.766: e-mail: fbotti@luiss.it

\$ University of Rome II "Tor Vergata", University of Rome I "La Sapienza”, and LUISS Guido Carli, Via O.Tommasini 1, 00162 Roma, Italy; fax: (39)06.86.506.605; telephone: (39)06.85.225.766: e-mail: aconte@luiss.it (corresponding author)

$£$ LUISS Guido Carli, Via O.Tommasini 1, 00162 Roma, Italy; fax: (39)06.86.506.605; telephone: (39)06.85.225.766: e-mail: ddicagno@,luiss.it

* University of Rome I "La Sapienza”, and LUISS Guido Carli, Via O.Tommasini 1, 00162 Roma, Italy; fax: (39)06.86.506.605; telephone: (39)06.85.225.766: e-mail: cdippoliti@luiss.it
\end{abstract}

- Sponsor: PRIN-2006, Project MCO53 


\section{RISK ATTITUDE IN REAL DECISION PROBLEMS}

This paper aims at providing new evidence on risk aversion, focussing on aggregation over individuals eliciting their heterogeneity. The relevance of this topic is twofold: from a theoretical point of view, by showing that differences among people significantly affect their decisions, we highlight the need for theoretical developments which can better account for diversity. From an applied viewpoint, the statistical significance of such individual factors allows for better estimates than the ones one obtains when disregarding this issue.

In lab experiments, individuals are observed as many times as the experimenter needs. This has provided ground for a flourishing literature focussing on the analysis of choice rules estimated individual by individual. Such a kind of approach is nearly unfeasible when data stemming from natural experiments are used. However, natural experiments' datasets are very attractive for they have the benefit of salient incentives. Therefore, in order to study choice rules when the number of observations on each individual is exogenously determined, researchers need to pool individual data.

Participants both in lab and natural experiments differ in crucial characteristics. In pooling their data, we cannot discard this fact. Using data from a natural experiment, namely a TV show, which involves players taking decisions between risky prospects with outcomes up to half-a- million euros, we estimate three models of decision making under risk: Expected Utility, Rank-Dependent Expected Utility and Regret-Rejoice. The characteristics of the game, which involves lotteries composed of small and very large prizes, allow us to investigate the performance of the Rank-Dependent Expected Utility 
(RD) and Regret-Rejoice (RR) utility functionals ${ }^{1}$ in addition to the standard Expected Utility (EU) functional.

Our research is designed to capture nuances in players' behaviour neglected by the EU formulation. Specifically, with the introduction of a RD functional, we can take into account the fact that some players appear to overweight the extreme prizes of a lottery with respect to the others; while the RR functional allows us to consider players' regretting or rejoicing considerations, when confronted with situations that could radically change their lives.

In order to give the choice models sufficient flexibility to fit the data, we introduce heterogeneity both in the form of observable and unobservable individual characteristics. The former includes everything concerning agents that can be observed, like gender or geographical origin; ${ }^{2}$ the latter involves all individual characteristics that cannot be observed, such as optimism or pessimism, cultural background, etc. In order to include unobserved heterogeneity in the choice models, we use econometric tools proper to the analysis of panel data and Monte Carlo simulation techniques.

We find significant roles both for observed and unobserved individual characteristics, showing that our estimates provide a superior fitting of the choice models than other studies. We also find that Regret-Rejoice does not significantly improve upon Expected Utility, while Rank-Dependent outperforms it. Interestingly, we find that the CARA specification fits significantly better than the conventionally-adopted CRRA specification. From our results we infer that individual-wise analyses can be satisfactorily substituted for by a pooled approach, without losing information on individual heterogeneity.

\footnotetext{
${ }^{1}$ Loomes and Sugden (1983); Quiggin (1993).

${ }^{2}$ Harrison and Rutström (2005).
} 
The paper is structured as follows. In section 1, the basic rules of the game are presented; section 2 highlights the econometric models to be estimated; in section 3 the empirical results are presented. Section 4 concludes. Additional results are reported in appendix.

\section{The game and the sample}

Television shows provide a good natural context in which ordinary people face welldefined decision problems in a ceteris paribus environment, and in which players have the benefit of salient incentives. Studies using such data are able to overcome both the Harrison and List (2004) and the Rabin (2000) critiques to experimental methods in economics, concerning the inferential validity of estimates based on the typical economic experiment, i.e. based on a non-representative sample and limited incentives provided by small money stakes.

Friend and Blume (1975), Gertner (1993), Metrick (1995) and Beetsma and Shotman (2001) measure individual risk attitude through television games in the US: Gertner (1993) and Friend and Blume (1975) obtain relatively high coefficients of risk aversion in data from the game Card Sharks and Beetsma and Shotman (2001) using data from the TV show Lingo; instead Metrick (1995) finds risk neutrality using data from the game Jeopardy!

We use data from the TV-show Affari tuoi, the Italian edition of the popular international format Deal or no Deal. The Italian game exhibits some relevant variations from the main international format. Specifically, it is developed as a 5-step stop-and-go game between a player and a Banker. The game starts with 20 players, one 
from each of the 20 Italian regions. They are randomly assigned 20 sealed boxes, each containing a prize drawn from a known distribution (see Table 1). Boxes' contents range from $€ 0.01$ to $€ 500,000$ : the average prize is $€ 52,545.83$, with a very high standard deviation $(€ 117,639.07)$ and a highly skewed distribution.

\section{TABLE 1 AROUND HERE}

One player is selected to actually play the game by means of a quick question: the fastest candidate who answers correctly plays the game. ${ }^{3}$ The game then proceeds as follows. In each of the 5 rounds, the player opens a fixed number of boxes ( 6 in the first round, 3 in the following), losing the possibility of winning the prizes contained therein. Between every two rounds, the Banker makes an offer: he either offers the player the opportunity to change her box with any of the remaining ones ("swap"), or he can offer a certain amount of money to the player to quit the game. If the player accepts the money, the game ends; otherwise she proceeds to the next round. If the player gets to the final round without having accepted any of the Banker's money offers, she wins the content of the box owned at that stage.

As Andersen et al. (2006a, 2006b, 2006c) notice, three main estimation strategies have been developed to test hypotheses on behaviour under risk within Deal or No Deal. We briefly discuss them here.

\footnotetext{
3 The questions are usually so naïve (e.g. the number of time the word "amore" appears in Dante's Divina Commedia) that no one can possibly answer but by chance. Hence, we will assume that players are randomly selected, though with a presumption of self-selection of the original 20 candidates of individuals keen of appearing on TV.
} 
The most simple method is to develop qualitative indicators which usually lead to scarce but definitive conclusions: for example, by comparing the money offer with the expected value of two remaining prizes at the last game round, risk-loving, indifference to risk, or risk-aversion can be easily inferred. Many authors make this kind of analysis as a preliminary step to more structured estimations, and Blvatskyy and Pogrebna (2006a and 2006b) use qualitative indicators to formally test alternative hypotheses about players' risk attitude. Such an analysis allows conducting individual-specific estimates, but its applicability is limited to a small set of research questions.

Alternatively, a bound approach is used. It is meant to provide upper and lower bounds for the risk attitude parameter according to players' behaviour during the game. The typical application assumes expected utility behaviour (EU), with CARA or CRRA preference functionals, implying that the highest offer rejected sets a maximum value for individual's risk aversion, while the offer possibly accepted sets a minimum value. The main advantage of this technique is that it also allows for individual-specific estimates, at the cost of providing only intervals of values, frequently not closed (for individuals who never accept the Banker's offers) and possibly empty (for individuals not behaving consistently to the simple choice model adopted). Henceforth, this method is employed in several works as a preliminary data analysis (exception being Deck et al. (2006) and Post et al. (2006)). Bombardini and Trebbi (2005) extend this analysis to an interval regression of the estimated bounds, in order to investigate the role of possible sources of observed heterogeneity among contestants.

Finally, it is possible to define a latent structural decision process and estimate a logit or probit model as a function of the model's parameters. This is the approach we follow as 
well as Andersen et al. (2006a, 2006b, 2006c), Mulino et al. (2006), Post et al. (2007), Sarafidis and de Roos (2006).

We analyse players' answers and consider only the instances when the Banker makes a monetary offer, because the models of behaviour we consider would predict perfect indifference over changing box. ${ }^{4}$

We represent players' decisions as a choice between the Banker's offer and a lottery which consists in the possibility of winning any of the remaining prizes with equal probability. In other words, we assume that contestants behave myopically, in they consider the possibility of winning one of the remaining prizes in a subsequent round of the game, but they neglect the future Banker's offers (or, which is the same, they assume that future offers will equal the expected value of the remaining prizes). It is worth noting that no clear consensus has been reached thus far about the validity of alternative hypotheses on players' myopia or on different degrees of forward-looking behaviour in the game. Several attempts have been made employing bound approaches, but these do not allow for a formal comparison of estimates, e.g. through some measures of goodness-of-fit. Sarafidis and de Roos (2006) propose the only attempt of fitting a structural model of both dynamic and static behaviours, using a database from the Australian edition of Deal or no Deal. Unfortunately, their estimates are based on samples of different length, and therefore the likelihood of the two models are noncomparable. Our sample is composed by 298 showings: although players are randomly selected, we observe men and women in a perfect one-half of the showings. Players are less evenly divided on geographical origin basis: in our sample we record 115 players from the North of Italy (39\% of the whole sample, 62 men and 53 women), 75 from the

\footnotetext{
${ }^{4}$ Blvatskyy and Pogrebna (2006a and 2006b) consider choices over the swap, on a subset of the Italian database.
} 
Centre (25\%, 36 and 39), and 108 from the South (36\%, 51 and 57). All regions are represented, ranging from 7 players from Calabria to 22 from Veneto.

Table 2 reports some summary statistics of the main characteristics of the sample.

\section{TABLE 2 AROUND HERE}

\section{The choice models}

We assume that during the game players are confronted with a sequence of binary choices between a lottery, where they can win one of the remaining boxes, each obviously with equal probability, and a degenerate lottery where they can win with probability 1 the amount of money offered by the Banker.

The game consists of 5 rounds, which we denote by $n$. We consider three different preference functionals: Expected Utility, Rank-Dependent Expected Utility and RegretRejoice. We assume that player $i$ 's utility function either takes the form of a Constant Absolute Risk Aversion (CARA) function, given by

$$
U_{i}(x)=\frac{-\exp \left(-R_{i} \cdot x\right)}{R_{i}}
$$

or by a Constant Relative Risk Aversion (CRRA) function, ${ }^{5}$ defined by

\footnotetext{
${ }^{5}$ The utility functionals are appropriately normalized, such that $U_{i}(0)=0$ and $U_{i}(\max (x))=1$.
} 


$$
U_{i}(x)=\frac{x^{1-R_{i}}}{1-R_{i}},
$$

where $x$ is the outcome and $R_{i}$ is a risk attitude parameter.

As noted before, we estimate players' preferences alternatively assuming EU, RD and RR preferences. We start with EU. Specifically, let $E U_{\text {in }}$ be the EU of the lottery in round $n$ for player $i$, that is the probability-weighted utility of each outcome left in round $n$,

$$
E U_{i n}=\sum_{k_{n}} p_{k_{n}} \cdot U_{i}\left(x_{k_{n}}\right)
$$

where $p_{k_{n}}$ is the probability of outcome $k$ in round $n$.

Let $U_{i}\left(o f f_{n}\right)$ be the utility of the amount offered to player $i$ in round $n$ by the Banker. Then, if player $i$ exhibits EU preferences, he or she chooses the option of playing the lottery or the option of accepting the amount offered, according to as $\nabla U_{\text {in }}^{*}$ is bigger or smaller than 0 , where $\nabla U_{i n}^{*}$ is defined by

$$
\nabla U_{\text {in }}^{*}=E U_{\text {in }}-U_{i}\left(o f f_{n}\right)+\varepsilon_{\text {in }} .
$$

Here $\varepsilon_{i n}$ is a Fechner-type error term (Hey and Orme, 1994) that we assume to be distributed normal, $\varepsilon_{i n} \sim N\left(0, \sigma_{\varepsilon}^{2}\right)$. It can be interpreted as a computational error individuals commit in calculating utilities: the bigger $\sigma_{\varepsilon}^{2}$, the bigger the error.

If, instead, the individual's preference functional is that of $\mathrm{RD}$, then we define $R D_{\text {in }}$ to be the RD of the lottery in round $n$ for player $i$,

$$
R D_{i n}=\sum_{k_{n}} \pi_{i k_{n}} \cdot U_{i}\left(x_{k_{n}}\right)
$$

where the prizes $x_{k_{n}}$ are sorted in decreasing order, with weights

$$
\pi_{i k_{n}}=w_{i}\left(p_{1_{n}}+\ldots+p_{k_{n}}\right)-w_{i}\left(p_{1_{n}}+\ldots+p_{(k-1)_{n}}\right),
$$


and

$$
w_{i}(p)=\frac{p^{\gamma_{i}}}{\left[p^{\gamma_{i}}+(1-p)^{\gamma_{i}}\right]^{1 / \gamma_{i}}} .
$$

$\gamma_{i}$ is the RD parameter. Thus, if $\gamma_{i}=1, \mathrm{RD}$ reduces to EU. Table 11 in the appendix reports the cumulative weighting functions for rank-dependent preferences $\left(w_{i}(p)\right)$ and the distributions of weights across prizes in decreasing order at each round $\left(\pi_{i k_{n}}\right)$. It is worth noting that, when $\gamma_{i}<1$, the two extreme prizes (the highest and the lowest) are over-valued with respect to the central, and this attitude increases as $\gamma_{i}$ goes to zero; moreover, the lowest prize gets a higher weight with respect to the highest, even if this relative distance reduces as $\gamma_{i}$ goes to 1 . When $\gamma_{i}>1$, the order of importance of the prizes is opposite (prizes at the centre of the spectrum are given more weight than those at the upper and lower ends), even if the lowest prize is still over-valued relatively to the highest at all rounds.

If player $i$ exhibits RD preferences, he or she chooses the option of playing the lottery or the option of accepting the amount offered, according as $\nabla U_{\text {in }}^{*}$ is bigger or smaller than 0 , where

$$
\nabla U_{i n}^{*}=R D_{i n}-U_{i}\left(o f f_{n}\right)+\varepsilon_{i n} .
$$

Finally, if instead the individual preference functional is that of RR theory and we denote $R R_{\text {in }}$ as the RR utility of the lottery in round $n$ for player $i$, relatively to the offer $o f f_{n}$,

$$
R R_{i n}=\sum_{k_{n}} p_{k_{n}} \cdot\left\{\begin{array}{l}
\left\lfloor U_{i}\left(x_{k_{n}}\right)-U_{i}\left(o f f_{n}\right)\right\rfloor \\
+2 \cdot \operatorname{sign}\left(U_{i}\left(x_{k_{n}}\right)-U_{i}\left(o f f_{n}\right)\right) \cdot \operatorname{abs}\left(U_{i}\left(x_{k_{n}}\right)-U_{i}\left(o f f_{n}\right)\right)^{a_{i}}
\end{array}\right\},
$$


where $a_{i}$ is the RR parameter. Thus, if $a_{i}=1$, also RR reduces to EU. If $a_{i}<1$, players experience regretting behaviours; while, if $a_{i}>1$, their choices are influenced by rejoicing considerations about the lottery and the money offer they are confronted.

If player $i$ exhibits RR preferences, he or she chooses the option of playing the lottery or the option of accepting the amount offered, according as $\nabla U_{i n}^{*}$ is bigger or smaller than 0 , where

$$
\nabla U_{\text {in }}^{*}=R R_{\text {in }}+3 \varepsilon_{\text {in }} .
$$

Actually, whatever the preference functional is, we observe the variable $\nabla U_{\text {in }}=1$ if individual $i$ in round $n$ chooses the lottery, and $\nabla U_{\text {in }}=0$ if individual $i$ in round $n$ chooses the offer. The three choice models are then described by:

$$
\begin{aligned}
& \nabla U_{i n}=1 \quad \text { if } \quad \nabla U_{i n}^{*}>0 \\
& \nabla U_{i n}=0 \quad \text { if } \quad \nabla U_{i n}^{*} \leq 0 .
\end{aligned}
$$

As each game is composed of several binary choices, for each player we observe a sequence of 0 's and 1's, corresponding to the player's choices at each stage of the game. Then, the likelihood contribution of player $i$ is the joint probability of observing the sequence of outcomes $\left(\nabla U_{i 1}, \ldots, \nabla U_{i N}\right)$,

$$
L_{i}=f\left(\nabla U_{i 1}, \ldots, \nabla U_{i N} \mid X_{i}, z_{i}, \alpha\right),
$$

where $X_{i}$ represents the time sequence of lottery prizes in player $i$ 's game and $N$ is the round player $i$ leaves the game.

To handle this joint probability we need to make assumptions on the error term $\varepsilon_{\text {in }}$ and on the independence of observations. In effect, as our sample contains repeated observations on the same contestant, we cannot discard the hypothesis that these observations are correlated. In a linear random-effects panel data model, this situation 
is generally handled by introducing an individual-specific intercept in the model, referred to as unobserved heterogeneity, which is assumed to have a particular distribution across individuals. What is left of the error term is therefore independent of everything else in the model. In contrast, our latent dependent variables are non-linear in the parameters to be estimated (eqq. 5, 11 and 15). In this case, to control for individual correlation we assume that there is a systematic individual-specific component in the risk aversion parameter, which is normally distributed across the population:

$$
R_{i}=\alpha+z_{i}^{\prime} \beta+u_{i}^{r a} .
$$

Here $\alpha$ is a constant, $z_{i}$ is a vector of observed demographic characteristics, and $u_{i}^{r a}$ reflects unobserved heterogeneity, with $u_{i}^{r a} \sim N\left(0, \sigma_{\varepsilon}^{2}\right)$, such that $R_{i} \sim N\left(\alpha+z_{i}^{\prime} \beta, \sigma_{r a}^{2}\right)$. When the preference functional is $\mathrm{RD}$, we also assume that the $\mathrm{RD}$ parameter is a function of demographic variables $\left(z_{i}\right)$ and unobserved heterogeneity $\left(u_{i}^{r d}\right)$ :

$$
\gamma_{i}=\gamma^{r d}+z_{i}^{\prime} \varphi+u_{i}^{r d}
$$

with

$$
\left(\begin{array}{c}
u_{i}^{r a} \\
u_{i}^{r d}
\end{array}\right) \sim N\left(\left(\begin{array}{l}
0 \\
0
\end{array}\right),\left(\begin{array}{cc}
\sigma_{r a}^{2} & \sigma_{r a, r d} \\
\sigma_{r a, r d} & \sigma_{r d}^{2}
\end{array}\right)\right) .
$$

Finally, when the considered preference functional is $R R$, we assume that the RR parameter is a function of a constant $(\alpha)$, demographic variables $\left(z_{i}\right)$ and unobserved heterogeneity $\left(u_{i}^{r \prime}\right)$,

$$
a_{i}=\gamma^{r r}+z_{i}^{\prime} \cdot v+u_{i}^{r r}
$$

with 


$$
\left(\begin{array}{l}
u_{i}^{r a} \\
u_{i}^{r r}
\end{array}\right) \sim N\left(\left(\begin{array}{l}
0 \\
0
\end{array}\right),\left(\begin{array}{cc}
\sigma_{r a}^{2} & \sigma_{r a, r r} \\
\sigma_{r a, r r} & \sigma_{r r}^{2}
\end{array}\right)\right) .
$$

After controlling for the unobserved heterogeneity, we are now allowed to assume that $\varepsilon_{i n}$ are independently and identically distributed and independent of everything else. We also allow for the possibility of sub-optimal behaviour, by introducing a tremble parameter, $\omega$. It measures the probability that players "tremble" in their choice. The tremble $\omega$ is zero if players behave optimally; on the contrary, it is 1 if they choose completely random. ${ }^{6}$

We can now write contestant $i$ 's likelihood contribution in the case of EU as

$$
\int_{-\infty}^{+\infty}\left\{\prod_{n}\left[(1-\omega) f\left(\nabla U_{i n} \mid X_{i}, z_{i}, \alpha, u_{i}^{r a}\right)+\frac{\omega}{2}\right]\right\} g\left(u_{i}^{r a}\right) d u_{i}^{r a}
$$

where $g($.$) is the probability density function of u_{i}^{r a}$.

In the case individual $i$ is a RD expected utility maximiser, her likelihood contribution is:

$$
\int_{-\infty}^{+\infty} \int_{-\infty}^{+\infty}\left\{\prod_{n}\left[(1-\omega) f\left(\nabla U_{i n} \mid X_{i}, z_{i}, \alpha, u_{i}^{r a}, u_{i}^{r d}\right)+\frac{\omega}{2}\right]\right\} h\left(u_{i}^{r a}, u_{i}^{r d}\right) d u_{i}^{r a} d u_{i}^{r d}
$$

where $h(.,$.$) is the joint density function of u_{i}^{r a}$ and $u_{i}^{r d}$.

Finally, in the case of RR preferences, it is instead:

$$
\int_{-\infty}^{+\infty} \int_{-\infty}^{+\infty}\left\{\prod_{n}\left[(1-\omega) f\left(\nabla U_{i n} \mid X_{i}, z_{i}, \alpha, u_{i}^{r a}, u_{i}^{r r}\right)+\frac{\omega}{2}\right]\right\} l\left(u_{i}^{r a}, u_{i}^{r r}\right) d u_{i}^{r a} d u_{i}^{r r}
$$

where $l(.,$.$) denotes the joint density function of u_{i}^{r a}$ and $u_{i}^{r r}$.

\footnotetext{
${ }^{6}$ See Moffatt and Peter (2001).
} 


\section{Main econometric results}

The three models presented in the previous paragraph are estimated by maximum simulated likelihood. ${ }^{7}$ Our sample consists of 298 players, observed 3.1 times on average. The distribution of $u_{i}^{r a}$ and the joint distributions $\left(u_{i}^{r a}, u_{i}^{r d}\right)$ and $\left(u_{i}^{r a}, u_{i}^{r r}\right)$ are simulated using 125 draws for each player based on Halton sequences. ${ }^{8}$ The estimates of the three models with both a CARA and a CRRA specification, without demographic variables, are reported respectively in tables 3 and $4 .{ }^{9}$

\section{TABLES 3 AND 4 AROUND HERE}

Both tables show that the mean of the risk aversion parameter ( $\alpha$ in all the specifications) is significantly bigger than 0 ; the mean of the $\mathrm{RD}$ parameter $\left(\gamma^{r d}\right)$ is significantly smaller than 1 ; the mean of the RR parameter $\left(\gamma^{r r}\right)$ is not significantly different from 1.

Furthermore, likelihood-ratio (see table 12) and BIC tests (reported at the bottom of each estimate) show that the RD specification always fits better than the EU and the RR specification, and that the latter never significantly improves the fitting over the EU model. $^{10}$

Finally, all the tremble parameters are statistically significant and small in magnitude, though bigger under the CRRA specification than with a CARA utility functional.

\footnotetext{
${ }^{7}$ Gourieroux and Monfort (1996).

${ }^{8}$ Train (2003).

${ }^{9}$ In fitting the models above, some of the parameters are appropriately constrained, so that: $\gamma_{i}>0$, $a_{i}>0, \sigma_{r a}, \sigma_{r d}, \sigma_{r r} \geq 0, \sigma_{\varepsilon} \geq 0$ and $0 \leq \omega \leq 1$. The standard errors of the transformed parameters are evaluated by the delta method (Oehlert, 1992).

${ }^{10}$ However, we should point out that, within the framework of Affari Tuoi, in certain circumstances RR preferences are not identifiable over expected utility. This is the case of the $5^{\text {th }}$ round, when players face choices between an amount of money and a lottery with only two prizes.
} 


\subsection{Unobserved Heterogeneity}

We notice that unobserved heterogeneity plays a crucial role in the estimates of the risk aversion parameter $\left(R_{i}\right)$, the RD parameter $\left(\gamma_{i}\right)$, and of the RR parameter $\left(a_{i}\right)$, as showed by the large magnitude of the estimated standard deviations of $u_{i}^{r a}, u_{i}^{r d}$, and $u_{i}^{r r}$ relatively to the constant part (respectively, $\alpha, \gamma^{r d}$ and $\gamma^{r r}$ ).

Moreover, there is a strong evidence of correlation between the unobserved heterogeneity terms in both the RD and the RR models, since $\rho_{r a, r d}=\sigma_{r a, r d} /\left(\sigma_{r a} \sigma_{r d}\right)$ and $\rho_{r a, r r}=\sigma_{r a, r r} /\left(\sigma_{r a} \sigma_{r r}\right)$ are always statistically significant, respectively positive and negative in sign. This result allows us to identify a systematic relationship among risk aversion, and RD and RR behaviours. In effect, a positive correlation in the RD model shows that the more risk averse a player is the bigger the RD parameter, and vice versa. This suggests that there is a tendency for the most risk loving players to overvalue the extreme prizes of the lottery they are playing with respect to the central; while the most risk averse tend to flatten their prizes' weight distribution. As far as the RR model is concerned, a negative correlation showed by the two unobserved heterogeneity terms implies that the more a player is risk averse the more she experiences regretting behaviours, such that the player tend to accept the offer more often with respect to EU players, ceteris paribus. On the contrary, the most risk loving players seem to rejoice more, accepting to play the lottery more often than players who have EU preferences, ceteris paribus.

The imposition of a panel data structure to the data through the introduction of the unobserved heterogeneity terms always improves the fitting over the models which do not use the information on the common origin of groups of observations, hence not 
allowing for a systematic attitude in each player's behaviour. This can be clearly seen by comparing the estimates in tables 3 and 4 with those in tables 8 and 9 in appendix.

As the BIC tests in tables 3,4,8 and 9 also show, in all our estimates, the CARA specification fits better than the CRRA specification independently of the preference functional ${ }^{11}$. This result is relevant since the majority of the experimental literature generally adopts only the CRRA specification. This argument, together with the one explained in the previous paragraph, induces us to consider EU and RD preferences with a CARA specification only in what follows.

Following the findings commented in this paragraph, in what follow we will focus on EU and RD models with a CARA utility functional. ${ }^{12}$

In unreported analysis, we also estimate the CRRA specification of the three models, assuming a non-zero life-time wealth as a parameter to be estimated, similarly to Andersen et al. (2006). We find that the long-life wealth parameter is significantly different from zero and close to $20,000 €$. Nevertheless, the use of these specifications never improves the fitting of our data over the CARA. ${ }^{13}$

\subsection{Demographics and framing effects}

To introduce observed heterogeneity, we include in our estimation a dummy sex and two geographical dummies (dummy north and dummy south) ${ }^{14}$. Also an end-of-period dummy has been introduced ( $5^{\text {th }}$ round dummy), which we interpret as a framing effect generated in early rounds when players face not a one-shot lottery but a sequence of

\footnotetext{
${ }^{11}$ See table 12 in appendix.

${ }^{12}$ Further results are available from the authors upon request.

${ }^{13}$ These results are available from the authors upon request.

${ }^{14}$ The introduction of demographics has the only effect to compute the mean of the risk aversion and the RD parameters for cohorts of players grouped on a gender and geographical basis.
} 
nested lotteries. EU and RD estimates including demographics and the $5^{\text {th }}$ round dummy are reported in tables 5 and 6 respectively.

In the EU model, specifications 2 and 3 listed in table 5, players gender does not significantly affect their risk aversion; ${ }^{15}$ by contrary, the significance of the parameter on the dummy north reveals players from the Centre and South of Italy to be relatively less risk averse than the others. Indeed, the fitting significantly improves over the estimate in table $3(\mathrm{EU})$ only when the $5^{\text {th }}$ round dummy is introduced, according to the likelihood-ratio tests. The statistical significance of this framing effect suggests that players are much more risk averse when confronted with a one-shot lottery, even if in those cases the tremble's magnitude increases.

With RD preferences, the parameters on the $5^{\text {th }}$ round dummy, both affecting players' risk aversion and RD attitudes, are never significant (table 6, specifications 1 and 3 ) in that they never improve the fitting. By contrary, the introduction of demographics definitely improves the fitting of the RD model, according to the likelihood-ratio test (see table 12 in appendix).

Concerning the estimates of the risk aversion parameter in the RD model with demographics (table 6, specifications 2 and 3), we observe that the mean of the risk aversion parameter for players from the North and from the South of Italy is slightly bigger than that of the others and that gender does not seem to have any influence on their risk attitude. Moreover, according to the Wald tests: the mean of the RD parameter for players from the South and North of Italy is slightly significantly smaller than 1, whatever their gender is; ${ }^{16}$ indeed, the sum of the coefficients on $\gamma^{r d}$, sex ${ }^{r d}$ and

\footnotetext{
${ }^{15}$ See Schubert et al. (1999)

${ }^{16} \mathrm{H}_{0}: \gamma^{r d}+$ dummy north ${ }^{r d}=1 \mathrm{v} / \mathrm{s} \mathrm{H}_{1}: \gamma^{r d}+$ dummy north ${ }^{r d}<1$; table $6(2), \chi_{2}^{2}=4.91534$ ( $p$-value $=0,0856$ ); table 6 (3), $\chi_{2}^{2}=5,09032(p$-value $=0.0785)$.
} 
alternatively on dummy north ${ }^{r d}$ and dummy south ${ }^{r d}$ is significantly smaller than 1 , with a value close to 0.54 , that is smaller than the mean $\mathrm{RD}$ parameter estimated without demographics in table 4 (that is significantly smaller than 1 and close to 0.76 ). ${ }^{17}$

\subsection{Self-selection}

At the beginning, we decided to introduce a $4^{\text {th }}$ and a $5^{\text {th }}$ round dummy among the explicative variables of risk aversion and RD parameters, to check for the presence of self-selectivity (attrition) in the sample; that is more risk averse players accept the offer at early rounds, quitting the game, and can no longer be observed. ${ }^{18}$ In the EU model, these two dummies are, counter-intuitively, statistically significant and positive (showing that players become more risk averse as the game progresses) and never significant in the RD (risk aversion attitude and rank-dependency do not eventually change).

Actually, the significance of the round dummies in the EU model is not necessarily a symptom of self-selection, but it can be simply explained by a money offer variation. ${ }^{19}$ To control for attrition bias, in unreported analysis, we complete the choice models with

$\mathrm{H}_{0}: \gamma^{r d}+$ dummy south ${ }^{r d}=1 \mathrm{v} / \mathrm{s} \mathrm{H}_{1}: \gamma^{r d}+$ dummy south ${ }^{r d}<1$; table $6(2), \chi_{2}^{2}=4.59661(p$-value $=0,1004) ;$ table 6 (3), $\chi_{2}^{2}=4.34664$ ( $p$-value $\left.=0,1138\right)$.

${ }^{17} \mathrm{H}_{0}: \gamma^{r d}+\operatorname{sex}^{r d}+$ dummy north ${ }^{r d}=1 \mathrm{v} / \mathrm{s} \mathrm{H}_{1}: \gamma^{r d}+\operatorname{sex}^{r d}+$ dummy north $^{r d}<1$; table $6(2), \chi_{3}^{2}=53.93776(p$-value $=$ $0.0000)$; table $6(3), \chi_{3}^{2}=46.09243(p$-value $=0.0000)$.

$\mathrm{H}_{0}: \gamma^{r d}+\operatorname{sex}^{r d}+$ dummy south ${ }^{r d}=1 \mathrm{v} / \mathrm{s} \mathrm{H}_{1}: \gamma^{r d}+\operatorname{sex}^{r d}+$ dummy south $h^{r d}<1$; table $6(2), \chi_{3}^{2}=91.56767(p$-value $=$ $0.0000) ; \chi_{3}^{2}=66.70482(p$-value $=0.0000)$.

${ }^{18}$ See tables 5 and 6 , specifications 1 and 3, for estimates including only the $5^{\text {th }}$ round dummy. Estimates including both of the round dummies are not included and are available from the authors upon request.

${ }^{19}$ In other words, imagine two players, equally risk averse, who have at round $n$ the same box situation; then, if the auctioneer makes them two different money offers, it is not unlikely that he offers to one of them more than his certainty equivalent, less to the other, such that only the first accepts the offer. This does not mean that the player who accepts is more risk averse than the other, and consequently self-selects, but that he has just got an offer which has pushed him to accept. 
a self-selection equation, as it is usually done in a standard panel tobit problem, ${ }^{20}$ demonstrating that the assumed selection process does not significantly affect the estimated parameters. Nonetheless, we present in the appendix (table 10) the selfselection equation to show that it does not give any suitable information to understand the selection process, since none of the variables seem to affect significantly the decision to stay or to quit the game. In the appendix (table 9) we present the selfselection equation to show that it does not give any suitable information to understand the selection process, since none of the variables seems to affect significantly the decision to stay or to quit the game. These arguments together with the almost complete dominance of the RD fittings over the more parsimonious EU allows us to conclude that self-selection is not an issue in our sample, and that the significance of the $4^{\text {th }}$ and $5^{\text {th }}$ round dummies in the EU model is simply explained by a misspecification of the functional form.

\section{Conclusions}

We use data from 298 showings of the television programme Affari Tuoi, which involves players taking decisions between risky prospects with outcomes up to half a million euros, to estimate three models of decision making under risk: Expected Utility theory, Rank-Dependent Expected Utility and Regret-Rejoice.

Among the competing choice models considered, the RD model seems always to fit the data best. It seems to capture the players' psychological attitude to overvalue or to

\footnotetext{
${ }^{20}$ J. Heckman (1979).
} 
undervalue extreme outcomes. We find instead that the EU model provides a better account of players' choice than the RR model, although the latter is not completely discarded as the heterogeneity term highlights that some players actually exhibit regret and rejoice behaviour.

Interestingly, in contrast with the prevailing experimental literature, we find that the CARA specification fits our data significantly better than the conventionally-adopted CRRA specification.

We take into account both observed and unobserved heterogeneity in players' behaviour. The latter allows us to obtain not just a point-estimate, but the whole distribution of the risk attitude parameter over the population. Unobserved heterogeneity definitely improves the fitting both of the risk aversion and of the RD weighting parameters. The presence of correlation between unobserved heterogeneity in risk attitude and alternatively rank-dependent and regret-rejoice behaviours allows us to identify a systematic relationship between these attitudes.

Observed heterogeneity accounting for gender seems not to matter in the EU choice model while it is relevant in the RD. Geographical origin explains part of RD behaviour, whereas it only slightly affects risk aversion.

Overall, the introduction of unobserved heterogeneity reduces significantly the standard deviation of the Fechner-noise error term. This means that, after controlling for heterogeneity in players' risk attitude, very few is left to be explained by the error term. The estimates of the tremble parameter show that just a small proportion of players choose completely at random. Its magnitude is close to $5 \%$ in the specification without unobserved heterogeneity, but it reduces to $0.3 \%$ when unobserved heterogeneity is included. 
Finally, we can conclude that individual-specific analyses can be satisfactorily substituted by an aggregate approach without losing relevant information about individual heterogeneity. 


\section{References}

Andersen S., Harrison G., Lau M., Rutström E. 2006a. Dynamic Choice Behavior in a Natural Experiment. Working Paper 06-10. Department of Economics, College of Business Administration, University of Central Florida

Andersen S., Harrison G., Lau M., Rutström E. 2006b. Risk Aversion in Game Shows. Working Paper 06-19. Department of Economics, College of Business Administration, University of Central Florida.

Beetma R., Shotman P. 2001. Measuring risk attitudes in a natural experiment: data from the television game show Lingo. The Economic Journal. 111, 821-848.

Blvatskyy P., Pogrebna G. 2006a. Loss aversion? Not with half-a-million on the table!. Institute of Empirical Research in Economics, Working Paper. n 274. University of Zurich.

Blavatskyy P., Pogrebna G. 2006b. Testing the predictions of decision theories in a natural experiment when half a million is at stake. Working Paper. Institute for Empirical Research in Economics, University of Zurich.

Bombardini M., Trebbi F. 2006. Risk aversion and EU theory: a field experiment with large and small stakes. Working Paper 05-20. Department of Economics, University of British Columbia.

Cameron A. C., Trivedi P. K. 2005. Microeconometrics: methods and applications. New York: Cambridge University Press.

Deck C., Jungmin L., Reyes J. 2006. Risk attitude in large stake gambles: Evidence from a game show. Working Paper. Department of Economics, University of Arkansas. 
de Roos N., Sarafidis S. 2006. Decision making under risk in Deal or No Deal. Working Paper. School of Economics and Political Science, University of Sydney.

Diecidue E., Wakker P.P. 2001. On the intuition of RD Utility, The Journal of Risk and Uncertainty. 23, 281-298.

Friend I., Blume M. B. 1975. The demand for risky assets. American Economic Review. $65,900-922$.

Fullenkamp C., Tenorio R., Battalio R. 2003. Assessing individual risk attitudes using field data from lottery games. Review of Economics and Statistics. 85, 218-26.

Gertner R. 1993. Game shows and economic behaviour: risk taking on "Card sharks". The Quarterly Journal of Economics. 108, 507-521.

Gourieroux C., Monfort A. 1996. Simulation-Based Econometric Methods. Oxford: Oxford University Press.

Harrison G. W., List J. 2004. Field experiments. Journal of Economic Literature. 42, 1009-55.

Hartley R., Lanot G., Walker I. 2005. Who really wants to be a millionaire: estimates of risk aversion from game show data. Working Papers. University of Warwick.

Heckman J. 1979. Sample selection bias as a specification error. Econometrica. 47, 153161.

Hersch P. L., McDougall G. S. 1997. Decision making under uncertainty when the stakes are high: evidence from a lottery game show. Southern Economic Journal. 64, $75-84$. 
Holt C. A., Laury, S. K. 2002. Risk aversion and incentive effects. American Economic Review. 92, 1644-55.

Loomes G., Moffatt P., Sugden R. 2002. A microeconometric test of alternative stochastic theories of risky choice. Journal of Risk and Uncertainty. 24, 103-130.

Loomes G., Sugden R. 1982. Regret Theory: An Alternative Theory of Rational Choice Under Uncertainty. Economic Journal. 92, 805-824.

Metrick A. 1995. A natural experiment in Jeopardy!. American Economic Review. 85, 240-253.

Moffatt P.G., Peters A.S. 2001. Testing for the presence of a tremble in economic experiments. Experimental Economics. 4, 221-228.

Mulino D., Scheelings R., Brooks R., Faff R. 2006. An empirical investigation of risk aversion and framing effects in the Australian version of Deal or No Deal. Working Paper. Department of Economics, Monash University, June 2006.

Peracchi F. 2001. Econometrics. John Wiley \& Sons, Chichester.

Post T., Baltussen G., Van den Assem M., Thaler R., 2007. Deal or no deal? Decision making under risk in a large-payoff game show. EFA 2006 Zurich Meetings Paper.

Quiggin J. 1993. Generalized EU Theory: The RD EU Model, Amsterdam: KluwerNijhoff.

Rabin M. 2000. Diminishing marginal utility of Wealth cannot explain Risk Aversion. in Kahneman, D., Tversky, A., (eds.), Choices, Values, and Frames, Cambridge: Cambridge University Press. 
Schubert R., Brown M., Gysler M., Brachinger H. W. 1999. Financial DecisionMaking: Are Women Really More Risk-Averse?, American Economic Review. 89, 381385 .

Stern S. 2000. Simulation Based Inference in Econometrics: Motivation and Methods. in Mariano, R.S., Weeks, M., Schuermann, T., (eds.) Simulation-Based Inference in Econometrics: Methods and Applications. Cambridge: Cambridge University Press.

Train K., 2003. Discrete choice methods with simulation. Cambridge: Cambridge University Press. 
Appendix

TABLES 7 TO 12 AROUND HERE 
Table 1. Prizes as displayed to players

\begin{tabular}{|c|c|}
$€ 0.01$ & $€ 5,000$ \\
\hline$€ 0.20$ & $€ 10,000$ \\
\hline$€ 0.50$ & $€ 15,000$ \\
\hline$€ 1$ & $€ 20,000$ \\
\hline$€ 5$ & $€ 25,000$ \\
\hline$€ 10$ & $€ 50,000$ \\
\hline$€ 50$ & $€ 75,000$ \\
\hline$€ 100$ & $€ 100,000$ \\
\hline$€ 250$ & $€ 250,000$ \\
\hline$€ 500$ & $€ 500,000$ \\
\hline
\end{tabular}


Table 2. Summary Statistics

\begin{tabular}{l|c|c|c|c|c|c|c|}
\hline & Players & $\begin{array}{c}\text { Swap } \\
\text { Offer }\end{array}$ & Acceptance & $\begin{array}{c}\text { Money } \\
\text { Offer }\end{array}$ & Mean & Std.Dev. & Acceptance \\
\hline Round 1 & 298 & 293 & 72 & 5 & $€ 3,200$ & $€ 1,351$ & 0 \\
\hline Round 2 & 298 & 9 & 4 & 289 & $€ 6,584$ & $€ 6,584$ & 4 \\
\hline Round 3 & 294 & 26 & 12 & 268 & $€ 7,790$ & $€ 7,790$ & 12 \\
\hline Round 4 & 284 & 33 & 9 & 251 & $€ 16,388$ & $€ 16,388$ & 80 \\
\hline Round 5 & 204 & 95 & 40 & 109 & $€ 32,844$ & $€ 49,304$ & 54 \\
\hline
\end{tabular}


Table 3. Parameter estimates; CARA utility functional; maximum simulated likelihood (298 groups, 923 obs.)

\begin{tabular}{|c|c|c|c|}
\hline & EU & $\mathrm{RD}$ & $\mathrm{RR}$ \\
\hline \multicolumn{4}{|c|}{ Estimates of risk aversion, $R D$ and $R R$ parameters } \\
\hline$\alpha$ & $\begin{array}{c}0.01039 \\
(0.00069)\end{array}$ & $\begin{array}{c}0.01119 \\
(0.00062)\end{array}$ & $\begin{array}{c}0.01103 \\
(0.00151)\end{array}$ \\
\hline$\gamma^{\text {rd }}$ & - & $\begin{array}{c}0.71734 \\
(0.05553)\end{array}$ & - \\
\hline$\gamma^{\mathrm{rr}}$ & - & - & $\begin{array}{c}1.12114 \\
(0.22299)\end{array}$ \\
\hline \multicolumn{4}{|c|}{ Estimates of the covariance matrix, scale parameters and tremble } \\
\hline$\sigma_{r a}$ & $\begin{array}{c}0.00322 \\
(0.00104)\end{array}$ & $\begin{array}{c}0.00345 \\
(0.00164)\end{array}$ & $\begin{array}{c}0.00296 \\
(0.00127)\end{array}$ \\
\hline$\sigma_{r d}$ & - & $\begin{array}{c}0.15134 \\
(0.00076)\end{array}$ & - \\
\hline$\sigma_{r r}$ & - & - & $\begin{array}{c}0.17911 \\
(0.02473)\end{array}$ \\
\hline$\rho_{r a, r d}$ & - & $\begin{array}{c}0.65916 \\
(0.03705)\end{array}$ & - \\
\hline$\rho_{r a, r r}$ & - & - & $\begin{array}{c}-0.58947 \\
(0.32492)\end{array}$ \\
\hline$\sigma_{\varepsilon}$ & $\begin{array}{c}0.05592 \\
(0.00498)\end{array}$ & $\begin{array}{c}0.06340 \\
(0.00657)\end{array}$ & $\begin{array}{c}0.05438 \\
(0.00586)\end{array}$ \\
\hline$\omega$ & $\begin{array}{c}0.04586 \\
(0.02008)\end{array}$ & $\begin{array}{c}0.03879 \\
(0.02131)\end{array}$ & $\begin{array}{c}0.04871 \\
(0.02008)\end{array}$ \\
\hline Log-likelihood & -305.05314 & -292.21631 & -304.37781 \\
\hline BIC statistics & 637.41680 & 639.05365 & 663.37767 \\
\hline
\end{tabular}

Robust standard errors in parentheses 
Table 4. Parameter estimates; CRRA utility functional; maximum simulated likelihood (298 groups, 923 obs.)

\begin{tabular}{|c|c|c|c|}
\hline & $\mathrm{EU}$ & $\mathrm{RD}$ & $\mathrm{RR}$ \\
\hline \multicolumn{4}{|c|}{ Estimates of the risk aversion, $R D$ and Regret parameters } \\
\hline$\alpha$ & $\begin{array}{c}0.39473 \\
(0.01786)\end{array}$ & $\begin{array}{c}0.32205 \\
(0.11711)\end{array}$ & $\begin{array}{c}0.38116 \\
(0.03019)\end{array}$ \\
\hline$\gamma^{\mathrm{rd}}$ & - & $\begin{array}{c}0.55655 \\
(0.12788)\end{array}$ & - \\
\hline$\gamma^{\mathrm{rr}}$ & - & - & $\begin{array}{c}0.95362 \\
(0.10198)\end{array}$ \\
\hline \multicolumn{4}{|c|}{ Estimates of the covariance matrix, scale parameters and tremble } \\
\hline$\sigma_{r a}$ & $\begin{array}{c}0.06737 \\
(0.01877)\end{array}$ & $\begin{array}{c}0.08074 \\
(0.07153)\end{array}$ & $\begin{array}{c}0.07175 \\
(0.01942)\end{array}$ \\
\hline$\sigma_{r d}$ & - & $\begin{array}{c}0.10690 \\
(0.00147)\end{array}$ & - \\
\hline$\sigma_{r r}$ & - & - & $\begin{array}{c}0.11028 \\
(0.09718) \\
\end{array}$ \\
\hline$\rho_{r a, r d}$ & - & $\begin{array}{l}-0.08896 \\
(0.25915)\end{array}$ & - \\
\hline$\rho_{r a, r r}$ & - & - & $\begin{array}{l}-0.04559 \\
(0.02062)\end{array}$ \\
\hline$\sigma_{\varepsilon}$ & $\begin{array}{c}0.02164 \\
(0.00381)\end{array}$ & $\begin{array}{c}0.01334 \\
(0.00293)\end{array}$ & $\begin{array}{c}0.02073 \\
(0.00447)\end{array}$ \\
\hline$\omega$ & $\begin{array}{c}0.16498 \\
(0.01865)\end{array}$ & $\begin{array}{c}0.17387 \\
(0.02346)\end{array}$ & $\begin{array}{c}0.16538 \\
(0.02164)\end{array}$ \\
\hline Log-likelihood & -365.52249 & -355.23462 & -364.92457 \\
\hline BIC statistic & 758.35549 & 765.09027 & 784.47017 \\
\hline
\end{tabular}

Robust standard errors in parentheses 
Table 5. Parameter estimates; EU; CARA utility functional; maximum simulated likelihood (298 groups, 923 obs.)

\begin{tabular}{|c|c|c|c|}
\hline & (1) & (2) & (3) \\
\hline \multicolumn{4}{|c|}{ Estimates of the risk aversion parameter } \\
\hline$\alpha$ & $\begin{array}{c}0.01009 \\
(0.00070)\end{array}$ & $\begin{array}{c}0.00835 \\
(0.00117)\end{array}$ & $\begin{array}{c}0.00849 \\
(0.00183)\end{array}$ \\
\hline $\operatorname{sex}^{\mathrm{ra}}$ & - & $\begin{array}{c}0.00131 \\
(0.00140)\end{array}$ & $\begin{array}{c}0.00031 \\
(0.00164)\end{array}$ \\
\hline Dummy north ${ }^{\mathrm{ra}}$ & - & $\begin{array}{c}0.00218 \\
(0.00154)\end{array}$ & $\begin{array}{c}0.00227 \\
(0.00183)\end{array}$ \\
\hline Dummy South $^{\text {ra }}$ & - & $\begin{array}{c}0.00181 \\
(0.00227)\end{array}$ & $\begin{array}{c}0.00183 \\
(0.00195)\end{array}$ \\
\hline $5^{\text {th }}$ round dummy ${ }^{\text {ra }}$ & $\begin{array}{c}0.02517 \\
(0.00579)\end{array}$ & - & $\begin{array}{c}0.02468 \\
(0.00659)\end{array}$ \\
\hline \multicolumn{4}{|c|}{ Estimates of the scale parameters and tremble } \\
\hline Std.Dev. $\left(\mathrm{u}_{\mathrm{i}}^{\mathrm{ra}}\right)$ & $\begin{array}{c}0.00275 \\
(0.00095)\end{array}$ & $\begin{array}{c}0.00357 \\
(0.00127)\end{array}$ & $\begin{array}{c}0.00298 \\
(0.00116)\end{array}$ \\
\hline$\lambda$ & $\begin{array}{c}0.04974 \\
(0.00506)\end{array}$ & $\begin{array}{c}0.05466 \\
(0.00505)\end{array}$ & $\begin{array}{c}0.04909 \\
(0.00510)\end{array}$ \\
\hline$\omega$ & $\begin{array}{c}0.07124 \\
(0.02011)\end{array}$ & $\begin{array}{c}0.04581 \\
(0.01934)\end{array}$ & $\begin{array}{c}0.07122 \\
(0.01989)\end{array}$ \\
\hline Log-likelihood & -297.30579 & -302.69075 & -295.98576 \\
\hline BIC statistics & 628.74972 & 653.17490 & 645.79255 \\
\hline
\end{tabular}

Robust standard errors in parentheses 
Table 6. Parameter estimates; RD; CARA utility functional; maximum simulated likelihood (298 groups, 923 obs.)

\begin{tabular}{|c|c|c|c|}
\hline & (1) & (2) & (3) \\
\hline \multicolumn{4}{|c|}{ Estimates of the risk aversion parameter } \\
\hline$\alpha$ & $\begin{array}{c}0.01137 \\
(0.00075)\end{array}$ & $\begin{array}{c}0.00870 \\
(0.00125)\end{array}$ & $\begin{array}{c}0.00892 \\
(0.00189)\end{array}$ \\
\hline $\operatorname{sex}^{\mathrm{ra}}$ & - & $\begin{array}{c}-0.00024 \\
(0.00141)\end{array}$ & $\begin{array}{c}-0.00026 \\
(0.00178)\end{array}$ \\
\hline Dummy north $^{\text {ra }}$ & - & $\begin{array}{c}0.00251 \\
(0.00183)\end{array}$ & $\begin{array}{c}0.00230 \\
(0.00206)\end{array}$ \\
\hline Dummy south $^{\text {ra }}$ & - & $\begin{array}{c}0.00262 \\
(0.00152)\end{array}$ & $\begin{array}{c}0.00245 \\
(0.00190)\end{array}$ \\
\hline $5^{\text {th }}$ round dummy ${ }^{\text {ra }}$ & $\begin{array}{c}-0.00361 \\
(0.00332)\end{array}$ & - & $\begin{array}{c}-0.00044 \\
(0.00262)\end{array}$ \\
\hline \multicolumn{4}{|c|}{ Estimates of the RD parameter } \\
\hline$\gamma^{\text {rd }}$ & $\begin{array}{c}0.76230 \\
(0.10948)\end{array}$ & $\begin{array}{c}1.12715 \\
(0.10275)\end{array}$ & $\begin{array}{c}1.11765 \\
(0.11496)\end{array}$ \\
\hline $\operatorname{sex}^{\text {rd }}$ & - & $\begin{array}{c}-0.25624 \\
(0.10469)\end{array}$ & $\begin{array}{c}-0.25682 \\
(0.09874)\end{array}$ \\
\hline Dummy north ${ }^{\text {rd }}$ & - & $\begin{array}{c}-0.33785 \\
(0.10755)\end{array}$ & $\begin{array}{c}-0.32537 \\
(0.12932)\end{array}$ \\
\hline Dummy South $^{\text {rd }}$ & - & $\begin{array}{c}-0.34809 \\
(0.10783)\end{array}$ & $\begin{array}{c}-0.33226 \\
(0.13515)\end{array}$ \\
\hline $5^{\text {th }}$ round dummy ${ }^{\text {rd }}$ & $\begin{array}{l}-0.24980 \\
(0.31212)\end{array}$ & - & $\begin{array}{c}-0.04277 \\
(0.10539)\end{array}$ \\
\hline \multicolumn{4}{|c|}{ Estimates of the covariance matrix, scale parameter and tremble } \\
\hline$\sigma_{r a}$ & $\begin{array}{c}0.00318 \\
(0.00211)\end{array}$ & $\begin{array}{c}0.00389 \\
(0.00111)\end{array}$ & $\begin{array}{c}0.00382 \\
(0.00114)\end{array}$ \\
\hline$\sigma_{r d}$ & $\begin{array}{c}0.13936 \\
(0.01454)\end{array}$ & $\begin{array}{c}0.06565 \\
(0.00071)\end{array}$ & $\begin{array}{c}0.06434 \\
(0.00059)\end{array}$ \\
\hline$\rho_{r a, r d}$ & $\begin{array}{c}0.60275 \\
(0.74944)\end{array}$ & $\begin{array}{c}0.46202 \\
(0.24520)\end{array}$ & $\begin{array}{c}0.47093 \\
(0.16500)\end{array}$ \\
\hline$\sigma_{\varepsilon}$ & $\begin{array}{c}0.06410 \\
(0.00903)\end{array}$ & $\begin{array}{c}0.05025 \\
(0.00655)\end{array}$ & $\begin{array}{c}0.05102 \\
(0.00817)\end{array}$ \\
\hline$\omega$ & $\begin{array}{c}0.03883 \\
(0.02994)\end{array}$ & $\begin{array}{c}0.04453 \\
(0.01691)\end{array}$ & $\begin{array}{c}0.04494 \\
(0.01710)\end{array}$ \\
\hline Log-likelihood & -291.28109 & -283.64643 & -283.49393 \\
\hline BIC statistics & 644.01084 & 656.05204 & 669.40229 \\
\hline
\end{tabular}

Robust standard errors in parentheses 


\begin{tabular}{cl}
\hline \hline $4^{\text {th }}$ round dummy & $\begin{array}{l}\text { dummy variable taking the value of } 1 \text { if the decision is } \\
\text { taken in the } 4^{\text {th }} \text { round, } 0 \text { otherwise }\end{array}$ \\
\hline $5^{\text {th }}$ round dummy & $\begin{array}{l}\text { dummy variable taking the value of } 1 \text { if the decision is } \\
\text { taken in the } 5^{\text {th }} \text { round, } 0 \text { otherwise }\end{array}$ \\
\hline Dummy sex & $\begin{array}{l}\text { dummy variable taking the value of } 1 \text { if the player is a } \\
\text { male, } 0 \text { otherwise }\end{array}$ \\
\hline Dummy north & $\begin{array}{l}\text { dummy variable taking the value of } 1 \text { if the player is } \\
\text { from the North of Italy, } 0 \text { otherwise }\end{array}$ \\
\hline Dummy south & $\begin{array}{l}\text { dummy variable taking the value of } 1 \text { if the player is } \\
\text { from the South of Italy, } 0 \text { otherwise }\end{array}$ \\
\hline Average prize & $\begin{array}{l}\text { dummy variable assuming a constant value equal to the } \\
\text { average of the remaining prizes }\end{array}$ \\
\hline Median prize & $\begin{array}{l}\text { dummy variable assuming a constant value equal to the } \\
\text { median of the remaining prizes }\end{array}$ \\
\hline Players' box prize & $\begin{array}{l}\text { dummy variable equal to } 1 \text { if the highest prize figures } \\
\text { among the remaining prizes, } 0 \text { otherwise }\end{array}$ \\
\hline
\end{tabular}


Table 8. Parameter estimates; CARA utility functional; maximum likelihood (923 obs.)

\begin{tabular}{|c|c|c|c|}
\hline & $\mathrm{EU}$ & $\mathrm{RD}$ & $\mathrm{RR}$ \\
\hline \multicolumn{4}{|c|}{ Estimates of the risk aversion, $R D$ and Regret parameters } \\
\hline$\alpha$ & $\begin{array}{c}0.01080 \\
(0.00052)\end{array}$ & $\begin{array}{c}0.01139 \\
(0.00068)\end{array}$ & $\begin{array}{c}0.01184 \\
(0.00082)\end{array}$ \\
\hline$\gamma^{\text {rd }}$ & - & $\begin{array}{c}0.67321 \\
(0.05602)\end{array}$ & - \\
\hline$\gamma^{\mathrm{rr}}$ & - & - & $\begin{array}{c}1.23824 \\
(0.16661)\end{array}$ \\
\hline$\sigma_{\varepsilon}$ & $\begin{array}{c}0.05841 \\
(0.00491)\end{array}$ & $\begin{array}{c}0.07141 \\
(0.00547)\end{array}$ & $\begin{array}{c}0.05768 \\
(0.00479)\end{array}$ \\
\hline$\omega$ & $\begin{array}{c}0.05192 \\
(0.00033)\end{array}$ & $\begin{array}{c}0.04420 \\
(0.00027)\end{array}$ & $\begin{array}{c}0.05461 \\
(0.00043)\end{array}$ \\
\hline Log-likelihood & -311.24400 & -298.20763 & -309.57329 \\
\hline BIC statistics & 642.97088 & 623.72577 & 646.45709 \\
\hline
\end{tabular}

Robust standard errors in parentheses 
Table 9. Parameter estimates; CRRA utility functional; maximum likelihood (923 obs.)

\begin{tabular}{|c|c|c|c|}
\hline & $\mathrm{EU}$ & $\mathrm{RD}$ & $\mathrm{RR}$ \\
\hline \multicolumn{4}{|c|}{ Estimates of the risk aversion, $R D$ and Regret parameters } \\
\hline$\alpha$ & $\begin{array}{c}0.40097 \\
(0.02989)\end{array}$ & $\begin{array}{c}0.46920 \\
(0.00068)\end{array}$ & $\begin{array}{c}0.01184 \\
(0.02446)\end{array}$ \\
\hline$\gamma^{\text {rd }}$ & & $\begin{array}{c}0.69248 \\
(0.07907)\end{array}$ & - \\
\hline$\gamma^{\mathrm{rr}}$ & - & - & $\begin{array}{c}0.69248 \\
(0.16661)\end{array}$ \\
\hline$\sigma_{\varepsilon}$ & $\begin{array}{c}0.02463 \\
(0.00464)\end{array}$ & $\begin{array}{c}0.03940 \\
(0.01125)\end{array}$ & $\begin{array}{c}0.05768 \\
(0.00479)\end{array}$ \\
\hline$\omega$ & $\begin{array}{c}0.16859 \\
(0.05373)\end{array}$ & $\begin{array}{c}0.12111 \\
(0.11288)\end{array}$ & $\begin{array}{c}0.05461 \\
(0.03343)\end{array}$ \\
\hline Log-likelihood & -370.06481 & -363.01662 & -369.77174 \\
\hline BIC statistics & 760.61251 & 753.34375 & 766.85399 \\
\hline
\end{tabular}

Robust standard errors in parentheses 
Table 10. Parameter estimates; selection equation; random effect probit

\begin{tabular}{cc}
\hline intercept & $\begin{array}{c}18.5844 \\
(587.375)\end{array}$ \\
\hline Dummy sex & 0.05429 \\
& $(0.41303)$ \\
\hline \multirow{2}{*}{ Dummy north } & 0.21038 \\
& $(0.49078)$ \\
\hline \multirow{2}{*}{ Dummy south } & 0.31424 \\
& $(0.52816)$ \\
\hline \multirow{2}{*}{$4^{\text {th }}$ round dummy } & -7.33598 \\
\hline \multirow{2}{*}{$5^{\text {th }}$ round dummy } & $(238.929)$ \\
\hline Log-likelihood & -15.2228 \\
\hline \hline n.obs. & -233.91526 \\
\hline n.groups & 1490 \\
\hline \hline Robustant & 298 \\
\hline
\end{tabular}

Robust standard errors in parentheses 
Table 11

$R D$ cumulative weighting functions $\left(w_{i}(p)\right)$ for different $\gamma_{i}$ and prizes' weight distribution by round $\left(\pi_{i k_{n}}\right)$

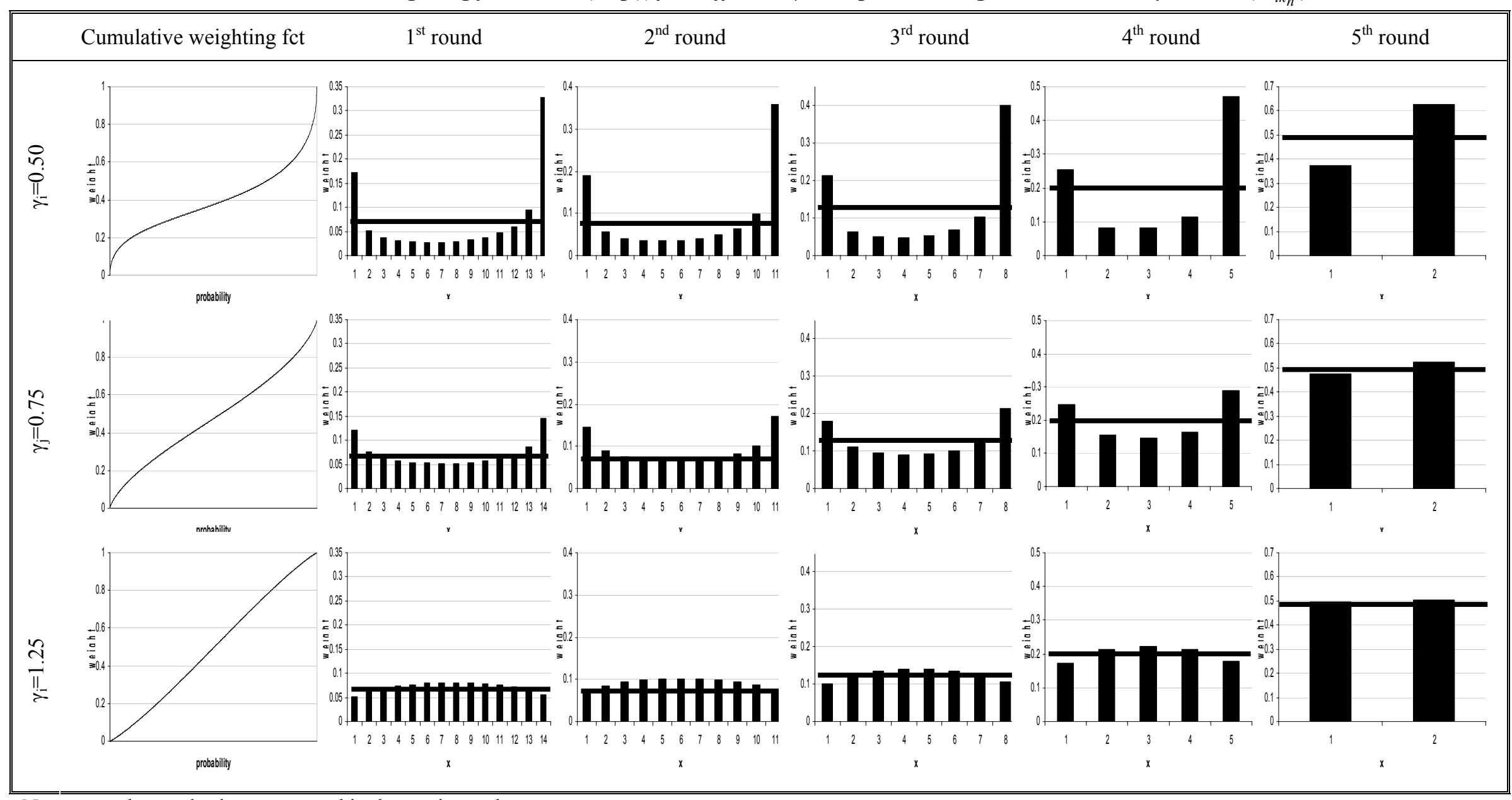

Note: at each round prizes are sorted in decreasing order 
Table 12: Likelihood ratio tests

\begin{tabular}{|c|c|c|c|}
\hline Competing models & $\begin{array}{l}\text { Likelihood-ratio } \\
\text { test statistic }\end{array}$ & \multicolumn{2}{|c|}{$p$-value of the test } \\
\hline Table $3(\mathrm{RD}) \mathrm{v} / \mathrm{s}$ table $3(\mathrm{EU})$ & 25.67906 & $\left(\chi_{3}^{2}\right)$ & 0.0000 \\
\hline Table $3(\mathrm{RR}) \mathrm{v} / \mathrm{s}$ table 3 (EU) & 1.3507 & $\left(\chi_{3}^{2}\right)$ & 0.7171 \\
\hline Table $4(\mathrm{RD}) \mathrm{v} / \mathrm{s}$ table $4(\mathrm{EU})$ & 20.57574 & $\left(\chi_{3}^{2}\right)$ & 0.0001 \\
\hline Table 4 (RR) v/s table 4 (EU) & 1.19584 & $\left(\chi_{3}^{2}\right)$ & 0.7540 \\
\hline Table $5(1) \mathrm{v} / \mathrm{s}$ table $3(\mathrm{EU})$ & 7.74735 & $\left(\chi_{1}^{2}\right)$ & 0.0054 \\
\hline Table $5(2) \mathrm{v} / \mathrm{s}$ table $3(\mathrm{EU})$ & 4.72478 & $\left(\chi_{3}^{2}\right)$ & 0.1931 \\
\hline Table 5 (3) v/s table 3 (EU) & 15.4947 & $\left(\chi_{4}^{2}\right)$ & 0.0038 \\
\hline Table $5(3) \mathrm{v} / \mathrm{s}$ table $5(1)$ & 2.64006 & $\left(\chi_{3}^{2}\right)$ & 0.4505 \\
\hline Table $6(1) \mathrm{v} / \mathrm{s}$ table $3(\mathrm{EU})$ & 21.5441 & $\left(\chi_{5}^{2}\right)$ & 0.0006 \\
\hline Table $6(2) \mathrm{v} / \mathrm{s}$ table $3(\mathrm{EU})$ & 42.81342 & $\left(\chi_{9}^{2}\right)$ & 0.0000 \\
\hline Table $6(3) \mathrm{v} / \mathrm{s}$ table $3(\mathrm{EU})$ & 43.11842 & $\left(\chi_{11}^{2}\right)$ & 0.0000 \\
\hline Table $6(1) \mathrm{v} / \mathrm{s}$ table $3(\mathrm{RD})$ & 1.87044 & $\left(\chi_{2}^{2}\right)$ & 0.3925 \\
\hline Table $6(2) \mathrm{v} / \mathrm{s}$ table $3(\mathrm{RD})$ & 17.13976 & $\left(\chi_{6}^{2}\right)$ & 0.0088 \\
\hline Table $6(3) \mathrm{v} / \mathrm{s}$ table $3(\mathrm{RD})$ & 17.44476 & $\left(\chi_{8}^{2}\right)$ & 0.0258 \\
\hline Table $6(3) \mathrm{v} / \mathrm{s}$ table $6(1)$ & 15.57432 & $\left(\chi_{6}^{2}\right)$ & 0.0162 \\
\hline Table $6(2) \mathrm{v} / \mathrm{s}$ table $6(3)$ & 0.30500 & $\left(\chi_{2}^{2}\right)$ & 0.8586 \\
\hline
\end{tabular}

